\title{
40 the great quantitative/ QUALITATIVE DEBATE: The Past, Present, and Future of Positivism and Post-Positivism in Information Systems
}

\author{
Michael D. Myers \\ University of Auckland \\ Detmar Straub \\ Georgia State University \\ John Mingers \\ University of Kent \\ Geoff Walsham \\ University of Cambridge
}

Over the past 20 years there has been significant progress in quantitative and qualitative research in information systems (Lee et al. 1997; Myers 1997; Myers and Avison 2002). There has also been much progress in our understanding of the contributions that can be made by both positivist and post-positivist (i.e., interpretive and critical) perspectives.

The purpose of this panel is to review the progress that has been made and to suggest the way forward for the future. The members of the panel will discuss the proposition that there has been progress in IS (measured by the effectiveness, explanatory power, and professionalism) in quantitative/qualitative and positivist/post-positivist research methods. As part of this discussion they will debate whether some of the progress has come from a greater openness to pluralistic research methods with the field of IS. They will also debate how and to what extent such pluralism is possible.

Michael Myers will begin by outlining the motivation for the debate. He will then introduce the panel members. 
Detmar Straub will review the progress that has been made in quantitative/ positivist research methods in IS. He will argue that what might be viewed as progress (i.e., toward more rigor in measurement and broader acceptance and practice of new methodological tools) might not be viewed as progress by non-positivists. Nevertheless, given that a case can be made for the philosophical position of positivism (which he will not undertake), he will next highlight areas where there has been progress and areas where there has been little to no progress. Slow progress has been made in measurement validation, for example, but experimentation has declined as a preferred approach, which raises issues about proving causation.

Michael Myers will review the progress that has been made in qualitative/ postpositivist research methods. He will argue that, while there has been a general acceptance of qualitative and more specifically interpretive research within IS, critical IS research has remained somewhat marginal.

John Mingers will argue that the best way forward for the field is for both qualitative and quantitative researchers to collaborate and for different research methods to be combined in the one study (Mingers 2001). He will suggest existing paradigms such as positivism and interpretivism are inherently limited in their different ways so that research conducted wholly from within a single paradigm must itself be limited and onesided. Research will be richer and more valid if it combines insights and methods from different paradigms. This can be under-written by a critical realist philosophy (Mingers, 2003).

Geoff Walsham will argue against collaboration and combining of research methodologies, broadly defined as sets of philosophical underpinnings of research activities. He will suggest that it is possible to collaborate and combine methods when there is a common philosophical base, but not when these philosophical bases are different.

Both Michael Myers and Detmar Straub will briefly comment on the various presentations, highlighting the main areas of debate.

\section{REFERENCES}

Lee, A. S.; Liebenau, J.; and DeGross, J. I. (Eds.). Information Systems and Qualitative Research, London: Chapman and Hall, 1997.

Mingers, J. "Combining IS Research Methods: Towards a Pluralist Methodology," Information Systems Research (12:3), 2001, pp. 240-259.

Mingers, J. "Real-izing Information Systems: Critical Realism as an Underpinning Philosophy for Information Systems," in L. Applegate, R. Galliers, and J. I. DeGross (Eds.),

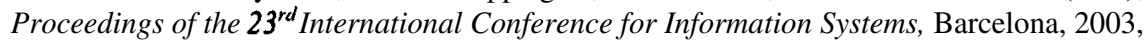
pp. 295-303.

Myers, M. D. "Qualitative Research in Information Systems," MIS Quarterly (21:2), 1997, pp. 241-242.

Myers, M. D., and Avison, D. E. (Eds.). Qualitative Research in Information Systems: A Reader, London: Sage Publications, 2002. 